\title{
PARALLEL-HF
}

\section{- A Paradigm Shift for Heart Failure Treatment in Japan? -}

\author{
Kyung-Duk Min, MD, PhD; Masafumi Kitakaze, MD, PhD
}

H eart failure (HF) has been a leading cause of mortality for decades worldwide and a novel therapeutic strategy for HF has always been awaited. Neurohormonal peptides, namely natriuretic peptides, bradykinin and adrenomedullin, are good targets because of their favorable effects on HF through attenuating vasoconstriction and sodium retention. Neprilysin is the key enzyme responsible for the breakdown of neurohormonal peptides, so a neprilysin inhibitor would retard the pathophysiology of HF through augmentation of the benefits from neurohormonal peptides. On the other hand, however, a neprilysin inhibitor is known to provoke counteractivation of the renin-angiotensin system (RAS), presumably because of degradation of angiotensin itself. Therefore, the use of a neprilysin inhibitor requires concurrent block of the RAS. In this context, the first attempt at a neprilysin inhibitor, sacubitril, for HF treatment was made by combining an angiotensin-converting enzyme inhibitor (ACEI) inhibitor, enalapril, but it resulted in serious angioedema as an adverse effect. ${ }^{1}$ To overcome this problem, an angiotensin-receptor neprilysin inhibitor (ARNI: sacubitril-valsaltan) was designed under the name of LCZ696. In 2014, amid strong need for HF therapy, the Prospective Comparison of ARNI with ACEI to Determine Impact on Global Mortality and Morbidity in Heart Failure (PARADIGM-HF) trial showed that sacubitril-valsaltan reduced $20 \%$ of mortality and hospitalization caused by HF compared with enalapril, so the study was terminated early because of the apparent benefit in the sacubitrilvalsaltan group. ${ }^{2}$ Based on this striking result, sacubitrilvalsaltan was approved by both the European Medicines Agency (EMA) and U.S. Food and Drug Administration (FDA) under the name of Entresto ${ }^{\circledR}$ in 2015, and now it is recommended in the latest guidelines for HF from the American Heart Association and the European Society of Cardiology.

Then, based on the result of PARADIGM-HF, should we switch ACEIs or ARBs to sacubitril-valsaltan in realworld clinical practice in Japan? The answer to this question has now been addressed by the Phase III prospective comparison of ARNI with ACEI to determine the noveL beneficiaL tReatment vaLue in Japanese Heart Failure patients (PARALLEL-HF) study. ${ }^{3}$

\begin{abstract}
Article p 2575
Although a substantial number of participants were enrolled from the Asia-Pacific region to derive conclusions about the results of PARADIGM-HF, the effect of sacubitril-valsaltan in Asian HF patients is still a matter for careful discussion. The PARADIGM-HF trial analyzed 8,399 cases enrolled from many different regions of the world: $602(7 \%)$ from North America, 1,680 (20\%) from Western Europe, 2,762 (33\%) from Central/Eastern Europe/ Russia, 1,433 (17\%) from Latin America and 1,487 (18\%) from the Asia-Pacific region. ${ }^{4}$ However, according to the Asia-Pacific patients' data, the benefit of sacubitril-valsaltan came very close to, but did not reach the statistical significance (hazard ratio [HR] 0.85, 95\% confidence interval [CI] $0.69-1.04$ for the primary endpoint). ${ }^{4}$ Also, Asian ethnicity fell short of showing a statistically significant benefit from sacubitril-valsaltan (shown in the table, ${ }^{2}$ indices not shown). PARADIGM-HF included patients from China, Philippines, Singapore, South Korea, Taiwan and Thailand, for the Asia-Pacific region, but not Japan. Geographic, economic and social confounders vary, even among Asian countries. Therefore, it is quite meaningful to determine the actual efficacy of sacubitril-valsaltan in Japanese HF patients in PARALLEL-HF.

The patient eligibility criteria of PARALLEL-HF largely followed those of PARADIGM-HF and 225 patients with $\mathrm{HF}$ and reduced ejection fraction (HFrEF) were selected during the enrollment period of 2015-2016 and are still in follow-up of clinical outcomes. In this issue of the Journal, Tsutsui et $\mathrm{al}^{5}$ describe the baseline characteristics of the patients enrolled in PARALLEL-HF. Compared with PARADIGM-HF, the participants in PARALLEL-HF were older (67.9 vs. 63.8 years of age) and included more males ( $85.8 \%$ vs. $78.2 \%)$ and showed lower blood pressure (122.3/72.8 vs. $128.4 / 77.8 \mathrm{mmHg}$ ), lower body mass index (BMI: 24.5 vs. $28.1 \mathrm{~kg} / \mathrm{m}^{2}$ ) and lower levels of NT-proBNP $(1,130$ vs. $1,612.5 \mathrm{pg} / \mathrm{mL})$. The majority of patients in PARALLEL-HF were in NYHA Class II (93.8\% vs. $64.6 \%)$. Interestingly, despite lower NT-proBNP levels and predominantly NYHA Class II participants in PARALLEL-HF, LVEF was comparable in both studies $(28.1 \%$ vs. $29.5 \%)$.
\end{abstract}

The opinions expressed in this article are not necessarily those of the editors or of the Japanese Circulation Society.

Received August 19, 2018; accepted August 22, 2018; released online September 13, 2018

Robert M. Berne Cardiovascular Research Center, University of Virginia, Charlottesville, VA (K.-D.M.), USA; Department of Clinical Research and Development, National Cerebral and Cardiovascular Research Center, Suita (K.-D.M., M.K.), Japan

Mailing address: Kyung-Duk Min, MD, PhD, Robert M. Berne Cardiovascular Research Center, University of Virginia, 415 Lane Rd, PObox 801394, Charlottesville, VA 22908, USA. E-mail: km9xv@virginia.edu

ISSN-1346-9843 All rights are reserved to the Japanese Circulation Society. For permissions, please e-mail: cj@j-circ.or.jp 
These differences are consistent with previously reported regional characteristics in Asia, as well as in Japan, and the overall characteristics of participants were comparable to those of PARADIGM-HF. As well, importantly, the characteristics of PARALLEL-HF were comparable to those of previous HFrEF trials implemented in Japan (J-EMPHASIS-HF, CHART2, JCARE-CARD), suggesting that PARALLEL-HF successfully enrolled a representative contemporary cohort of HFrEF in Japan and that the results of PARALLEL-HF infer a clinical effect of sacubitrilvalsaltan for HF treatment in daily practice in Japan. Also, the aforementioned regional characteristics (i.e., older age, low BMI, low blood pressure) resulted in higher MAGGIC risk scores and higher EMPHASIS-HF scores in PARALLEL-HF compared with PARADIGM-HF. Importantly, in PARADIGM-HF, a higher MAGGIC risk score or EMPHASIS-HF score was associated with larger absolute benefit from sacubitril-valsaltan, ${ }^{6}$ implying potential benefit of sacubitril-valsaltan for Japanese HFrEF patients.

It is also noteworthy that, in this article, the authors provide the clinical data after the run-in period. The run-in dose of sacubitril-valsaltan $50 \mathrm{mg}$ bid for 2 weeks resulted in only 2 cases of run-in failure because of adverse events while significant changes in blood pressure $(121.8 / 72.6$ to $117.5 / 70.4 \mathrm{mmHg}, \mathrm{P}<0.01)$ and heart rate $(73.3$ to 74.9 beats $/ \mathrm{min}, \mathrm{P}<0.01)$ were observed. It shows, at least, that most of the participants in PARALLEL-HF - and presumably a large number of Japanese HFrEF patients - would be able to take this new drug at the minimum dose without adverse effects and be eligible for uptitration to a higher dose. In PARALLEL-HF, participants who completed the run-in period were randomized to receive sacubitril-valsaltan $100 \mathrm{mg}$ bid or enalapril $5 \mathrm{mg}$ bid for 4 weeks and, if tolerable, doses were uptitrated to $200 \mathrm{mg}$ bid and $10 \mathrm{mg}$ bid, respectively. ${ }^{3}$ The ARB component of sacubitril-valsaltan $200 \mathrm{mg}$ bid is equivalent to valsaltan $320 \mathrm{mg} /$ day, which is twice the maximum dose of valsaltan in Japan. This dose was shown to be tolerable for Japanese patients with hypertension, ${ }^{7}$ but whether it is tolerable for Japanese HF patients remains unknown. In this context, it is important that PARALLEL-HF allowed participants to take their "tolerable maximum dose", whereas all the participants of PARADIGM-HF took the target dose of sacubitril-valsaltan $200 \mathrm{mg}$ bid. Actually, in PARADIGM$\mathrm{HF}, 42 \%$ of patients in the sacubitril-valsaltan arm had to reduce the dose after randomization. ${ }^{8}$ Of interest, however, is that although the risk of the patients who had a dose reduction was higher than that of those who went through on the maximum dose (HR 2.5, 95\% CI 2.2-2.7), the treatment benefit of sacubitril-valsaltan over enalapril still remained comparable even after dose reduction (HR 0.80 , $95 \%$ CI 0.70-0.93). The "residual effect" of an initial high dose could be a possible explanation. But this result may simply imply the superiority of sacubitril-valsaltan over enalapril even at the lower dose. The results of PARALLEL$\mathrm{HF}$ could also approach this issue.

The results of PARADIGM-HF generated the enthusiasm of cardiologists all over the world and it is believed to be the key to a new era of HF treatment. PARALLEL-HF was designed as the phase III trial to test the clinical effect of sacubitril-valsaltan in HFrEF patients in Japan, but harbors huge potential to provide fundamental information for unanswered questions about the usage of sacubitrilvalsaltan in the real world, not limited to Japan. We shall await its results in 2019.

\section{References}

1. Kostis JB, Packer M, Black HR, Schmieder R, Henry D, Levy E. Omapatrilat and enalapril in patients with hypertension: The Omapatrilat Cardiovascular Treatment vs. Enalapril (OCTAVE) trial. Am J Hypertens 2004; 17: 103-111.

2. McMurray JJ, Packer M, Desai AS, Gong J, Lefkowitz MP, Rizkala AR, et al. Angiotensin-neprilysin inhibition versus enalapril in heart failure. $N$ Engl J Med 2014; 371: 993-1004.

3. Tsutsui H, Momomura S, Saito Y, Ito H, Yamamoto K, Ohishi T, et al. Efficacy and safety of sacubitril/valsartan (LCZ696) in Japanese patients with chronic heart failure and reduced ejection fraction: Rationale for and design of the randomized, double-blind parallel-HF study. J Cardiol 2017; 70: 225-231.

4. Kristensen SL, Martinez F, Jhund PS, Arango JL, Belohlavek J, Boytsov S, et al. Geographic variations in the PARADIGM-HF heart failure trial. Eur Heart J 2016; 37: 3167-3174.

5. Tsutsui H, Momomura S, Saito Y, Ito H, Yamamoto K, Ohishi $\mathrm{T}$, et al. Angiotensin receptor neprilysin inhibitor in Japanese patients with heart failure and reduced ejection fraction: Baseline characteristics and treatment of PARALLEL-HF trial. Circ $J$ 2018; 82: 2575-2583.

6. Simpson J, Jhund PS, Silva Cardoso J, Martinez F, Mosterd A, Ramires F, et al. Comparing LCZ696 with enalapril according to baseline risk using the MAGGIC and EMPHASIS-HF risk scores: An analysis of mortality and morbidity in PARADIGMHF. J Am Coll Cardiol 2015; 66: 2059-2071.

7. Rakugi H, Kario K, Yamaguchi M, Okino N, Gotou H, Zhang J. Efficacy and safety of LCZ696 compared with olmesartan in Japanese patients with systolic hypertension. Hypertension 2014; 64: A474.

8. Vardeny O, Claggett B, Packer M, Zile MR, Rouleau J, Swedberg K, et al. Efficacy of sacubitril/valsartan vs. enalapril at lower than target doses in heart failure with reduced ejection fraction: The PARADIGM-HF trial. Eur J Heart Fail 2016; 18: $1228-1234$. 